\title{
Pedagogía creativa, una estrategia docente en el nivel medio superior
}

José Manuel Muñoz Arellano

\section{Resumen}

$\mathrm{H}$ aciendo un análisis de la educación tradicional y la actual, podemos encontrar que algunos elementos han cambiado por completo: la participación del alumno, las técnicas, las metodologías, los roles y el aprendizaje. De igual manera, aumenta la necesidad de prácticas que permitan a los alumnos interesarse en lo que están aprendiendo; sin embargo, no es sencillo mantener esta motivación hacia el conocimiento, los docentes nos hemos convertido en verdaderos artistas construyendo escenarios educativos cada vez más favorables, con la ayuda de la tecnología, dinámicas, juegos, paseos, entre otros, posibilitando nuevas experiencias que detonen aprendizajes para la vida. Desafortunadamente, hay momentos en los que se acaban las ideas y los recursos, por ello la importancia de fortalecer este talento creativo, que permita diseñar experiencias significativas de enseñanza para conducir de manera diferente el proceso educativo de nuestros alumnos, apoyándonos en una pedagogía creativa.

Palabras clave: creatividad, estrategias, aprendizaje, enseñanza, estilos de aprendizaje.

Hablar de creatividad en un contexto educativo permite visualizar diversas áreas en las que se puede aplicar: con los docentes, con los alumnos, en las metodologías de enseñanza y de aprendizaje, entre otras. Esta actividad se convierte en una poderosa herramienta para propiciar aprendizajes significativos en el nivel medio superior. Es precisamente en este nivel que encontramos características muy particulares, entre ellas la pérdida de atención e interés hacia el contenido de cada asignatura, lo que supone que las estrategias docentes en el proceso de enseñanza no despiertan el interés de los alumnos, de ahí que nos cuestionamos sobre el impacto que tiene la práctica educativa.

La encargada de darle sentido a esta práctica es la Pedagogía, considerada como "la disciplina, el estudio o conjunto de normas, que se refieren a un hecho o a un proceso o actividad, la educación" (Nassif, 1958: 3). Reflexionando acerca de esta definición, se rescata la importancia de que esta actividad sea cada vez más interesante para los alumnos, considerando sus necesidades y aprovechando sus habilidades. La pedagogía, y en especial la didác- tica, que es rama de la primera, se adecuan a las diversas necesidades educativas, lo que implica hacer ajustes constantes en las prácticas para desarrollar aprendizajes significativos que nos acompañen a lo largo de nuestra vida.

Lograr que nuestros alumnos desarrollen sus habilidades no es una tarea fácil, la tecnología se ha convertido en un arma de doble filo en nuestros escenarios educativos; por un lado, permite crear escenarios que acercan a los alumnos a la realidad aumentada, todo al alcance de nuestros dispositivos móviles; por otro lado, las redes sociales logran "colarse" en nuestras aulas sin que el propio alumno tenga control sobre sí mismo, provocando una distracción o "fugas de atención" que rompen la dinámica del proceso de enseñanza y aprendizaje. Alexander Ortiz Ocaña (2015) nos comparte que, en un ambiente de aprendizaje, si la información que entra no es novedosa, sin emoción, el cerebro la procesa desde un plano inconsciente a través de procesos mecánicos, provocando que no haya aprendizaje ni cambio en las estructuras del cerebro; caso contrario si la información es 
novedosa, producida a través de una emoción, se empiezan a liberar grandes cantidades de dopamina que permite conectar diversas áreas del cerebro y lo dispone para el aprendizaje, este proceso asegura que la información llegue hasta la memoria a largo plazo, para que el alumno pueda disponer de ella ante cualquier situación que se requiera.

En la actualidad, tenemos la gran ventaja de conocer los estilos de aprendizaje de nuestros estudiantes, conformados por conductas o desempeños predecibles; sin embargo, no es suficiente, nos damos cuenta de que no sólo es cuestión de conocerlos y adecuar nuestras estrategias para facilitar el proceso de aprendizaje, sus características tienden a ser cada vez más diversas. Es precisamente por este aspecto que no podemos centralizar todas nuestras estrategias al estilo de los alumnos que predomina en este momento, puesto que puede ser cambiante respecto a lo que van experimentando; se requiere del diseño de estrategias "multisensoriales" que abarquen el mayor número de estilos de aprendizaje posibles que se puedan encontrar en el salón de clase.

Considerando el contexto anteriormente mencionado y el compromiso de brindar una formación integral, es conveniente potenciar una pedagogía creativa que involucre a los alumnos en su propio proceso de aprendizaje, avanzando a su ritmo y utilizando sus propias herramientas, que sirvan de base para dominar otro tipo de competencias con mayor nivel de complejidad. Además, la creatividad es una de las habilidades más importantes que realiza nuestro cerebro, y en la actualidad un talento bien valorado. De acuerdo con Paulo Freire (2006), rescatamos la importancia de una pedagogía creativa por el hecho de ser una necesidad que requieren los estudiantes para estimularla en procesos de búsqueda del conocimiento. En cuanto a los aspectos que giran en torno a la creatividad, vale la pena rescatar un poco de su historia, se menciona que:

La aparición de este vocablo fue en el Oxford English Dictionary en 1875 y la conferencia Creativity impartida en 1950 por el psicólogo Joy Paul Guilford en la Asociación Americana de Psicología. En esta conferencia Guilford presentó la creatividad como un instrumento de trabajo relacionado con las capacidades de la mente y las facultades superiores del hombre (Edwards, 2012).
《 Es conveniente potenciar una pedagogía creativa que involucre a los alumnos en su propio proceso de aprendizaje, avanzando a su ritmo y utilizando sus propias herramientas, que sirvan de base para dominar otro tipo de competencias con mayor nivel de complejidad. $\gg$

Existe una gran cantidad de definiciones que enriquecen el concepto, una de ellas nos menciona que creatividad "es la capacidad de pensar flexiblemente que se manifiesta a través de diversas alternativas de solución (por lo general, no convencionales) a las necesidades o problemas que se presentan" (Sánchez, 2004: 14); por lo tanto, se requiere el uso del pensamiento divergente que nos marca una nueva ruta para la solución de los problemas. Esta forma de pensar rompe con la lógica tradicional, buscando nuevas alternativas; es justo este principio el que debe estar presente en nuestra práctica educativa para el diseño de estrategias de enseñanza y aprendizaje.

Se reconoce el concepto de estrategia de aprendizaje como "una herramienta cognitiva que un individuo utiliza para solucionar o completar una tarea específica que dé como resultado la adquisición de algún conocimiento" (Riding y Rayner, 1999: 17). Teniendo como objetivo principal la adquisición de ese conocimiento que se construye entre todos los participantes del proceso educativo, las estrategias cobran un alto grado de importancia, puesto que permitirán trazar la ruta para obtenerlo. Como docentes nos damos cuenta del ajuste de nuestras estrategias de enseñanza dirigidas a generaciones diferentes; la metodología que funciona con una, no es la misma que necesita la que viene, ni mucho menos una anterior, por ello, nos percatamos de la necesidad de innovarse constantemente para enfrentar el reto que viene con cada generación.

En consonancia con la anterior idea, podemos mencionar a María Montessori y Waldorf, quienes son ejemplo claro de adecuar estas estrategias con gran esencia creativa en escenarios educativos. Es fácil entender su idea al conocer la manera en la que conciben el proceso, ambos tienen la creencia de que los niños, desde que nacen, tienen un enorme potencial, le dan un gran peso a las actividades artísticas en sus procesos de desa- 
rrollo, las condiciones se adaptan a las necesidades de los estudiantes, mantienen una esencia familiar en los centros educativos, entre otros; definitivamente, los resultados se presentan como una nueva y diferente experiencia de formación. Al respecto, en escenarios de educación media superior, vale la pena mencionar a Csikszentmihalyi (1998: 16) quien afirma que:

Una manera obvia de potenciar la creatividad es introducir al máximo en los diversos campos la experiencia de flujo. Resulta emocionante cons- truir la cultura: ser artista, científico, pensador o persona de acción. Con demasiada frecuencia, sin embargo, no se consigue comunicar el gozo del descubrimiento a los jóvenes, y éstos, por su parte, recurren a diversiones pasivas.

En respuesta a lo anterior, se presentan las siete estrategias de la creatividad propuestas por Ponti y Ferras (2006), como una alternativa de pedagogía creativa para el diseño de las metodologías de enseñanza centradas en el estudiante de nivel medio superior; en el orden referido por el mismo autor:

\begin{tabular}{|c|c|c|c|c|c|c|}
\hline 1 & 2 & 3 & 4 & 5 & 6 & 7 \\
\hline $\begin{array}{c}\text { THINK } \\
\text { ZEN }\end{array}$ & $\begin{array}{c}\text { THINK } \\
\text { PO }\end{array}$ & $\begin{array}{c}\text { THINK } \\
\text { OPEN }\end{array}$ & $\begin{array}{c}\text { THINK } \\
\text { FLOW }\end{array}$ & $\begin{array}{c}\text { THINK } \\
\text { \& DRAW }\end{array}$ & $\begin{array}{c}\text { THINK } \\
\text { HAPPY }\end{array}$ & $\begin{array}{c}\text { THINK } \\
\text { TEAM }\end{array}$ \\
\hline
\end{tabular}

THINK ZeN (Pensar "zen")

Con esta estrategia se busca percibir la realidad en sí misma, sin que esté alterada por nuestro pensamiento. 'La creatividad en su estado más auténtico tiene que ver con un cierto grado 'zen' que cada persona debe encontrar. La mente demasiado embotada es un obstáculo para la generación de ideas. La mente vacía, relajada y tranquila, es un enorme receptáculo para todo tipo de ideas" (Ponti y Ferras, 2006:82). Si partimos aplicando esta estrategia, estaremos disponiendo a nuestros alumnos para prepararse al proceso de aprendizaje de una manera diferente; en algunos centros se aplica practicando yoga como una de sus disciplinas, que pretende desarrollar un equilibrio físico y mental. No se busca que se aplique esta disciplina, sino adecuar estrategias que permitan cumplir el objetivo; la tranquilidad de la mente para identificar nuestra propia percepción de las cosas, identificar mi propio proceso de aprendizaje, sin miedo.

\section{THINK Po (Pensar "po")}

Esta estrategia está relacionada con la importancia de desarrollar experiencias "multisensoriales" en un nuevo escenario de aprendizaje; supone una alteración del sentido que lo reta a darle solución. Es una provocación que "implica una cierta deconstrucción de la realidad: a través de la reducción al absurdo nos damos cuenta de obviedades, y sólo a partir de ahí somos capaces de buscar ideas disruptivas" (Ponti y Ferras, 2006: 84). Para su desarrollo bien podemos utilizar actividades como: acertijos, adivinanzas y problemas contextualizados, entre otras situaciones didácticas que rompan con la lógica que el alumno tiene memorizada, y lo obliguen a trazar una nueva ruta para la solución. Estos conflictos cognitivos lo llevan por el pensamiento divergente. Edward de Bono (1998) es el que mejor conoce este concepto, haciendo referencia a él con el nombre de pensamiento lateral,' mismo que no busca la sustitución del pensamiento vertical sino enriquecerlo; el primero es creativo y el segundo selectivo.

1 De Bono (1998: 11) describe que el pensamiento lateral "está íntimamente relacionado con los procesos mentales de la perspicacia, la creatividad y el ingenio. Todos ellos tienen la misma base, pero se diferencian en que mientras estos tres últimos tienen un carácter espontáneo, independiente de la voluntad, el pensamiento lateral es más susceptible de ser determinado por la voluntad consciente". 


\section{THINK OPEN (Abrir la mente)}

Esta estrategia es una invitación a participar en otros contextos ajenos a los nuestros, con la finalidad de no limitar nuestra forma de pensar, seguro hay algo diferente a lo que hacemos; este encuentro diverso permite enriquecer nuestras propias ideas y extiende el conocimiento hacia aquello en lo que no estamos familiarizados. Si buscamos una pedagogía creativa que permita la innovación, debemos estar en contacto con otras personas y aprender de ellos, estar dispuestos a conocer. "La curiosidad típica de las personas creativas impulsa a mirar en otras realidades, meterse en mundos distintos $\mathrm{y}$, lo más importante, hacer transferencias, aplicaciones de una realidad a otra" (Ponti y Ferras, 2006:86).

\section{THINK FLow (Pensar con fluidez)}

Para el diseño de estrategias de enseñanza, utilizando este principio, se deberá considerar la flexibilidad de pensamiento. Hemos mencionado la importancia del pensamiento lateral para la solución de problemas; en este caso, el proceso lógico inicial es el primero de muchos que se pueden encontrar, para ello, debemos transitar por la ruta que el pensamiento divergente vaya descubriendo. "Tener fluidez creativa es básico para ser creativo. Sin fluidez hay bloqueo, y el bloqueo es la negación de la creatividad" (Ponti y Ferras, 2006:89). Buscamos en el pensamiento la fluidez que despierte en nuestros alumnos una motivación intrínseca para explorar nuevos horizontes. Posiblemente podemos encontrarnos con frases que arruinan la creatividad tales como: “¡Yo no puedo con esto!", “YY si me equivoco?”, "¡Yo no sé de esto!”, “¿Qué van a pensar si fracaso?", "Tengo todo qué perder, mejor no", entre otras, ¿se te hacen conocidas?, tal vez estén a la orden del día con nuestros alumnos, mientras desarrollan determinadas tareas de la asignatura.

\section{THINK \& DRAW (Pensar y dibujar)}

El siguiente aspecto sugiere el uso de organizadores gráficos, "use mapas mentales para desarrollar ideas, proyectos o procesos. Practique el Think \& Draw y comprobará cómo las ideas fluyen más, se hacen vivas, penetran en las mentes de las personas y desatan torrentes de creatividad" (Ponti y Ferras, 2006:93). En esta estrategia se busca materializar el pensamiento a través de imágenes que permitan el mejor entendimiento de un tema, así como simplificar información y tener una mejor experiencia de aprendizaje de quien lo realiza; además, es una estrategia ideal para aquellos alumnos que desarrollan un estilo de aprendizaje visual, puesto que construyen imágenes que representan ideas, lo que permite abordar una mayor cantidad de información y relacionar conceptos. Tony Buzan (2004) menciona más beneficios: potenciar la creatividad, ahorrar tiempo, solucionar problemas, concentrarse, organizar más eficientemente los pensamientos, aclarar ideas, aprobar los exámenes con mejores resultados, estudiar más rápido y eficientemente, tener una visión global de las cosas, planificar, comunicar, entre otros.

\section{THINK HAPPY (Pensar feliz)}

La motivación es el objetivo principal de esta estrategia, recupera la importancia de impulsar a nuestros estudiantes en el propio proceso de aprendizaje. Vale la pena reflexionar acerca de nuestras propias estrategias y la manera que impactan en nuestros alumnos ante nuevas generaciones, nuevas características y estilos, por lo tanto, se requiere hacer de lado las prácticas tradicionales que dejan estático al alumno en su propio proceso. Es importante que, a través de las actividades, se despierten todos los sentidos para disponer a nuestro cerebro a un mejor ambiente, en el que el alumno va descubriendo poco a poco sus habilidades. "Conocer nuestras auténticas motivaciones nos puede permitir enfocar mucho más nuestra creatividad" (Ponti y Ferras, 2006:93). 


\section{THINK TEAm (Pensar en equipo)}

En el ámbito de colaboración y trabajo en equipo, el Nuevo Modelo Educativo de Educación Media Superior 2018, descrito en el perfil de egreso del estudiante, establece que el alumno "Trabaja en equipo de manera constructiva, participativa y responsable, propone alternativas para actuar y solucionar problemas. Asume una actitud constructiva" (SEP, 2017:27). Para lograr este objetivo se requieren diversas estrategias dentro y fuera del salón de clase, al ser una competencia de aprendizaje para la vida, es importante estimular el proceso creativo para diseñar y aplicar actividades que despierten un sentido de colaboración y no de competencia para la construcción de un ambiente armónico. Ponti y Ferras (2006) establecen que la creatividad y cooperación son grandes amigas; de hecho, no hay una gran idea sin colaboración.

La aportación que se realiza con base en estas siete estrategias para potenciar el talento creativo, busca ser una herramienta docente para ampliar las posibilidades de propiciar un proceso educativo creativo y de calidad, no cabe duda que algunas de las estrategias que ya implementamos cubren alguna de ellas y analizando el impacto que tienen podemos visualizar algunas otras que puedo gestionar desde mi asignatura en el bachillerato.

Finalmente, tal como establece la primera estrategia, este proceso inicia desde nuestro ser docente para poder implementarlo en el salón de clase. Potenciar nuestra habilidad creativa para que de esta manera pueda permear sobre nuestra práctica educativa deberá ser una tarea diaria. "Los grandes sistemas necesitan grandes líderes. Es evidente que los alumnos mejorarán su rendimiento escolar si los estimulan profesores que sepan motivarlos, y que las escuelas evolucionarán favorablemente si tienen un director con visión de futuro" (Robinson, 2016: 300). En definitiva, si el alumno experimenta prácticas novedosas y significativas en el proceso de aprendizaje, el docente que las ha diseñado se convierte en un profesor modelo que, teniendo un objetivo, desarrolla experiencias inigualables.

\section{Fuentes de consulta}

Buzan, T. (2004). Cómo crear mapas mentales. Madrid: Urano.

Csikszentmihalyi, M. (1998). El fluir y la psicología del descubrimiento y la invención. Barcelona: Paidós.

De Bono, E. D. (1998). El pensamiento lateral: Manual de creatividad. México: Paidós.

Edwards, M. (2012). Innovación, blog sobre invención y creatividad de tendencias 21. Recuperado de:

https://www.tendencias21.net/innovacion/Que-es-la-creatividad_a37.html.

Freire, P. (2006). Pedagogía de la autonomía. Madrid: Siglo XXI de España editores, s.A.

Nassif, R. (1958). Pedagogía general. Buenos Aires: Kapelusz.

Ortiz, A. (2015). Neuroeducación. Bogotá: Ediciones de la U.

Ponti, F. y Ferras, X. (2006). Pasión por innovar: de la idea al resultado. Barcelona: Granica.

Recio, H. (2004). Creatividad en la solución de problemas. México: Trillas.

Riding, R. y Rayner, S. (1999). Cognitive Styles and Learning Strategies: Understanding Style Differen-

ces in Learning and Behavior. Londres: David Fulton Publishers.

Robinson, K. (2016). Escuelas creativas. México: Grijalbo.

Sánchez, H. R. (2004). Creatividad en la solución de problemas. México:Trillas.

SEP (2017). Planes de estudio de referencia del marco curricular común de la educación media superior. Recuperado de: http://www.sems.gob.mx/work/models/sems/Resource/12491/4/images/libro.pdf. 